\title{
Originalist Methodology
}

\author{
Lawrence B. Solum $\dagger$
}

This Essay sketches an originalist methodology using ideas from legal theory and theoretical linguistics, including the distinctions between interpretation and construction and between semantics and pragmatics. The Essay aims to dispel a number of misconceptions about the methods used by originalists. Among these is the notion that originalists rely on dictionary definitions to determine the communicative content of the constitutional text. Although dictionaries may play some role, the better approach emphasizes primary evidence such as that provided by corpus linguistics. Another misconception is that originalists do not consider context; to the contrary, the investigation of context plays a central role in originalist methodology.

Part I of this Essay articulates a theoretical framework that draws on ideas from contemporary legal theory and linguistics. Part II investigates methods for determining the constitutional text's semantic content. Part III turns to methods for investigating the role of context in disambiguating and enriching what would otherwise be sparse semantic meaning. Part IV describes an originalist approach to constitutional construction. The Essay concludes with a short reflection on the future of originalist methodology.

\section{INTRODUCTION}

"Originalism" is a family of contemporary theories of constitutional interpretation and construction that share two core ideas. First, the communicative content of the constitutional text is fixed at the time each provision is framed and ratified-the Fixation Thesis. ${ }^{1}$ Second, constitutional practice should be constrained by that communicative content of the text, which we can call the "original public meaning"-the Constraint Principle. ${ }^{2}$

$\dagger$ Carmack Waterhouse Professor of Law, Georgetown University Law Center. I owe thanks to the participants in The University of Chicago Law Review Symposium on "Developing Best Practices for Legal Analysis," which led to the Symposium Issue in which this Essay appears, and to participants at a faculty workshop at Georgetown University Law Center. I owe special thanks to Gregory Klass and Louis Michael Seidman for the their very helpful suggestions and criticisms. My thanks as well to Johanna Schmidt for valuable research assistance. (C) 2017 by Lawrence B. Solum.

1 See generally Lawrence B. Solum, The Fixation Thesis: The Role of Historical Fact in Original Meaning, 91 Notre Dame L Rev 1 (2015).

2 See generally Lawrence B. Solum, The Constraint Principle: Original Meaning and Constitutional Practice (unpublished manuscript, 2017) (on file with author). 
Other matters (for example, original intent versus original public meaning) are debated by contemporary originalists.

The core commitments to fixation and constraint imply two tasks for originalist methodology: (1) providing a set of tools and practices that can reliably discover the fixed communicative content of the constitutional text and (2) guiding constitutional practice. In other words, originalist methods must enable us to determine what the original meaning is and which actions are consistent with that meaning.

The originalist methodology sketched here uses ideas from legal theory and theoretical linguistics, including the distinctions between interpretation and construction and between semantics and pragmatics. For the sake of simplicity, most of the following discussion focuses on one portion of the constitutional text, the unamended text that was drafted in 1787. Part I of this Essay articulates a theoretical framework that draws on ideas from contemporary legal theory and linguistics. Part II investigates methods for determining the constitutional text's semantic content. Part III turns to methods for investigating the role of context in disambiguating and enriching what would otherwise be sparse semantic meaning. Part IV describes the application of these methods to constitutional construction. The Essay concludes with a short reflection on the future of originalist methodology.

\section{THE THEORETICAL FRAMEWORK}

The development of an originalist methodology requires a theoretical framework, the elaboration of which can begin with the idea of meaning itself.

\section{A. The Meaning of "Meaning"}

The word "meaning" is ambiguous and is used in at least three distinct senses in legal discourse: ${ }^{3}$

- Application meaning consists of the implications of a legal text for particular cases or issues, for example, "the meaning of the First Amendment in this context is that the president will not be able to sue successfully for defamation."

\footnotetext{
3 For a discussion of the ambiguity of "meaning," see C.K. Ogden and I.A. Richards, The Meaning of Meaning: A Study of the Influence of Language upon Thought and of the Science of Symbolism 305-36 (Harcourt, Brace 1923).
} 
- Teleological meaning is the goal or purpose for which a text is adopted, for example, "the meaning of the Equal Protection Clause was to ensure that the property and personal security rights of former slaves would be protected to the same degree as were the rights of other persons."

- Communicative meaning is the linguistic meaning or communicative content of a text, for example, "the communicative content of the word 'dollar' as used in the Seventh Amendment refers to the Spanish silver dollar weighing 416 grains."

Both application meaning and teleological meaning play a role in originalist constitutional theory, but these senses of "meaning" are not the sense used in the phrase "original meaning." The "original meaning" of the constitutional text is the original communicative content.

\section{B. Communicative Content and Legal Content}

Let us stipulate the following definitions of "communicative content" and "legal content":

- Communicative content is the content that the drafter intended to convey to the audience at which the text was aimed. ${ }^{4}$

- Legal content is the content assigned to the text by relevant legal authorities, for example, by the Supreme Court when it gives the Constitution an authoritative legal construction. ${ }^{5}$

In the constitutional context, legal content and communicative content can differ in several ways. For example, the legal content of constitutional doctrine might be richer than the communicative content of the constitutional text. The phrase "freedom of speech"6 has sparse communicative content, but the legal content of free speech doctrine is very rich. Another example is provided by the phrase "Congress shall make no law,"7 which communicates a limitation on the power of the Congress of the United

See id at 306, 312-16.

5 See Lawrence B. Solum, Communicative Content and Legal Content, 89 Notre Dame L Rev 479, 507-18 (2013).

6 US Const Amend I.

7 US Const Amend I. 
States; the legal content of free speech doctrine currently applies to executive and judicial action as well. ${ }^{8}$ Communicative content and legal content can differ, but they can also be identical. The clear directive that each state shall have two and only two senators $^{9}$ may be an example of this kind of direct translation or equivalence.

C. Interpretation and Construction

This Essay uses the words "interpretation" and "construction" in stipulated technical senses, as follows:

- Constitutional interpretation is the activity that discerns the communicative content (linguistic meaning) of the constitutional text.

- Constitutional construction is the activity that determines the content of constitutional doctrine and the legal effect of the constitutional text (including the decision of constitutional cases by the courts).

The phrase "interpretation-construction distinction" is used to designate the distinction as articulated in this way. ${ }^{10}$

\section{The Situation of Constitutional Communication}

The communicative meaning of a text is partially a function of the conventional semantic meaning of the words and phrases as they are composed into larger units by syntax. Unenriched semantic meaning, however, is sparse. The full communicative content of a text is also a function of context. Therefore, determining the meaning of constitutional texts requires an account of the situation of constitutional communication-a specification of the relevant context.

1. The idea of constitutional communication.

Begin with the simple and intuitive idea of constitutional communication. The authors of a constitutional text are attempting to communicate some content to future readers. Constitutional communication is continuous with other forms of linguistically

8 See David A. Strauss, The Living Constitution 56 (Oxford 2010).

See US Const Art I, $\S 3$.

10 For additional discussion of constitutional interpretation and constitutional construction, see generally Lawrence B. Solum, Originalism and Constitutional Construction, 82 Fordham L Rev 453 (2013). 
mediated human communication. Written constitutions are like other texts, using the resources of a natural language to convey communicative content to readers.

Written communication delivers content, but that content is not fully determined by semantics and syntax. This fact is wellknown to lawyers. The meaning of an utterance or writing is almost always partly a function of the context in which the communication occurs. In the philosophy of language and theoretical linguistics literature, the study of the role of context in communication is called "pragmatics." 11

2. The question of constitutional authorship.

Who is the "author" of each provision of the constitutional text? This is a difficult question because the creation of the constitutional text was a complex process in which multiple individuals and multiple institutions played significant roles. The text of the Constitution proposed by the Philadelphia Convention in 1787 was the product of a multistage process - the Convention voting on resolutions and further work done in the Committee of Detail and then the Committee of Style. ${ }^{12}$ Much of the actual language came late in the Convention, with James Wilson playing a major role in the Committee of Detail and Gouverneur Morris completing most of the actual drafting work in the Committee of Style, but with subsequent amendments on the floor of the Convention. ${ }^{13}$

But the Constitution drafted in 1787 was proposed by the Philadelphia Convention and then ratified by ratifying conventions (institutions, not individuals) held in the several states. ${ }^{14}$ In some sense, these institutions might be considered "authors" of the constitutional text, giving rise to well-known problems of group agency and group intentions. ${ }^{15}$ For present purposes, the important point is to recognize the complexity of constitutional

11 See Kepa Korta and John Perry, Pragmatics (Stanford Encyclopedia of Philosophy, Apr 2, 2015), online at http://plato.stanford.edu/archives/win2015/entries/pragmatics (visited Oct 23, 2016) (Perma archive unavailable).

12 See Gregory E. Maggs, A Concise Guide to the Records of the Federal Constitutional Convention of 1787 as a Source of the Original Meaning of the U.S. Constitution, 80 Geo Wash L Rev 1707, 1717-23 (2012).

13 See id at 1720-23.

14 See Gregory E. Maggs, A Concise Guide to the Records of the State Ratifying Conventions as a Source of the Original Meaning of the U.S. Constitution, 2009 U Ill L Rev 457, 466-68.

15 For a classic discussion of these problems, see Max Radin, Statutory Interpretation, 43 Harv L Rev 863, 870-71 (1930). 
authorship as a multistage process involving both individuals and groups engaged in both drafting and promulgation of the text.

3. The question of constitutional readership.

Describing the situation of constitutional communication requires identifying the readership to whom content was addressed. Just as framing was a multistage process, so too was and is the process of reading the Constitution. Fragments of the text of the Constitution were drafted in 1787 by individuals and then read by others at the Convention. Thus, Morris might have written a draft version of a clause, which was then read by other members of the Committee of Style and subsequently by the members of the Philadelphia Convention as a whole. The same clause, embedded in the whole text, would then have been read by the members of the public, then by members of the ratifying conventions, and then by citizens and officials. ${ }^{16}$ This process of reading continues today.

Because the meaning of the constitutional text is in part a function of the context of constitutional communication, it is important to determine the appropriate group of readers. For example, consider the unlikely possibility that the only audience for the text was the members of the Philadelphia Convention. In that case, the events at the Convention would be part of the relevant context. Other candidates for the intended readership include the members of the ratifying conventions, the public at large, or the limited audience of lawyers, officials, and judges.

The importance of this problem can be illustrated by considering an extreme possibility: that the intended readership was limited to the members of the Supreme Court. Consider the hypothesis examined by Howard Graham in his 1938 articles on the "conspiracy theory" of the Fourteenth Amendment.17 Suppose that those who drafted a given constitutional provision were able to agree on a secret or coded meaning and that the authoritative

16 There is an interesting theoretical question as to whether the relevant readership is the whole public or whether it should be limited to citizens. For practical purposes, this question is unlikely to have an effect on originalist methodology, because citizens are unlikely to constitute a distinct linguistic subcommunity. There is one important qualification to that hypothesis: it is possible that some groups of noncitizens, including slaves and native Americans, would be considered members of the public but would constitute a linguistic subcommunity. That issue is bracketed for the purposes of this Essay.

17 See generally Howard Jay Graham, The "Conspiracy Theory" of the Fourteenth Amendment, 47 Yale L J 371 (1938); Howard Jay Graham, The "Conspiracy Theory" of the Fourteenth Amendment: 2, 48 Yale L J 171 (1938). 
interpreters of the provision, that is, the justices of the Supreme Court, were in on the conspiracy. Here is Graham's statement of the argument:

Social historians have contended that the equal protection and due process clauses were designed to take in "the whole range of national economy;" that John A. Bingham, the member of the Joint Committee chiefly responsible for the phraseology of Section One, "smuggled" these "cabalistic" clauses into a measure ostensibly drafted to protect the Negro race. ${ }^{18}$

If this hypothesis were true, then the meaning of the Fourteenth Amendment would be a function of the special meanings that the justices recognized that Bingham intended to communicate to them, and those meanings might be radically different from the meanings that other readers such as members of Congress, ratifiers, and the public would have been able to access. The point of the example is not that this interpretation of the communicative situation is plausible; rather, it is to show that communicative content depends on the specification of the situation of constitutional communication.

4. The public meaning interpretation of the communicative situation.

Public meaning originalism is premised on a particular understanding of the situation of constitutional communication. The key idea is that the participants in the complex process of authorship intended to make the communicative content of the constitutional text accessible to the public at the time the text went through the ratification process. There is substantial evidence that supports the claim, including the following facts: (1) the Preamble begins with the words "We the People," 19 (2) the ratification process was consistently described as involving the citizenry at large, ${ }^{20}$ (3) the ratifying conventions were popularly elected, ${ }^{21}$ (4) the debate over ratification was conducted in public through publicly accessible media (pamphlets and newspapers)

\footnotetext{
18 Graham, 48 Yale L J at 171 (cited in note 17).

19 US Const Preamble.

20 See Robert N. Clinton, A Brief History of the Adoption of the United States Constitution, 75 Iowa L Rev 891, 910 (1990).

21 See George Gordon Battle, The Ratification of the Constitution, 64 US L Rev 576, 579 (1930).
} 
and in public meetings, ${ }^{22}$ and (5) the Constitution itself identifies the relevant form of government as "Republican"23 (from res publica-a public thing). ${ }^{24}$

The public meaning interpretation specifies that the relevant communicative intention is to make the communicative content of the text accessible to the public. This formulation needs qualification. First, the claim is not that the communicative situation excluded other audiences, including the ratifiers and judges; they were part of the public readership. Second, the claim is not that the full communicative content was immediately known to all members of the public who read the text: some of the content may have been contained in technical language (for example, "ex post facto Law" 25 ) accessible via the division of linguistic labor between experts (lawyers) and other members of the public. Third, public accessibility is not universal accessibility: some members of the public did not speak English, and others may have had various impairments such that the meaning of the text would have been inaccessible to them.

E. The Role of Theoretical Linguistics and the Philosophy of Language

What role do theoretical linguistics and the philosophy of language play in originalist methodology? We can approach this question by examining the relationship of theory to the natural competence of speakers of a natural language.

1. Theory, intuition, and natural competence.

The communicative content of oral and written communication in a natural language is generally accessible to speakers of the language because of their natural competence. Children acquire linguistic competence, enabling them to understand the language(s) spoken by their parents and others. Children do not need to learn theoretical linguistics and the philosophy of language in order to speak and understand English. The same thing is true of

\footnotetext{
22 See, for example, William P. Murphy, State Sovereignty and the Ratification of the Constitution-I, 33 Miss L J 29, 49-50 (1961).

23 US Const Art IV, $\S 4$.

24 These claims are simply asserted on this occasion. Their defense will be undertaken in The Public Meaning Thesis, a work in progress. See generally Lawrence B. Solum, The Public Meaning Thesis: Communicative Content Is the Original Meaning of the Constitutional Text (unpublished manuscript, 2017) (on file with author).

25 US Const Art I, §§ 9-10.
} 
other competencies. One does not need to study engineering or materials science to build a tree house or even a simple bridge across a small river.

Nonetheless, knowledge of engineering may be relevant to developing a methodology of bridge building. Our intuitive knowledge of physics and materials science does not exhaust the set of useful methodological principles. Folk psychology enables us to predict human behavior in a wide variety of circumstances, but in some cases behavioral economics will enable us to do a better job. Folk linguistics may enable us to discover the meaning of a very old text, but in some cases the tools of modern linguistic science may do a better job. Theoretical knowledge about the nature of communication may be helpful in determining the communicative content of the constitutional text-especially those parts of the text that are old and potentially the subject of linguistic drift.

2. The model theory: A neo-Gricean approach.

There is theoretical disagreement in the philosophy of language and theoretical linguistics literature. Every plausible view in these fields must be consistent with basic surface-level facts, but different theories may give different explanations of those facts at a deeper level. In this Essay, I adopt a neo-Gricean approach $^{26}$ to a variety of issues and bracket the question whether this theory is true or correct in light of rival views.

Stipulate the following understanding of the communicative content of writings in general:

The communicative content of a writing is the content the author intended to convey to the reader via the audience's recognition of the author's communicative intention. ${ }^{27}$

How do authors gain recognition of their communicative intentions? One mechanism is the use of conventions, including both conventional semantic meanings and syntax. ${ }^{28}$ Thus, as I

\footnotetext{
26 See Nicholas Allott, Key Terms in Pragmatics 132 (Continuum 2010) (defining the neo-Gricean approach to pragmatics in terms of a small number of basic ideas, including the idea "that the useful information in what is said should be maximized ... and an opposed but complementary principle that what the speaker says should be minimized"); Laurence R. Horn, A Natural History of Negation 192-203 (Chicago 1989) (explaining the origins and implications of the neo-Gricean model).

27 See Solum, 89 Notre Dame L Rev at 480-84 (cited in note 5).

28 See id at 486-89, 491-94.
} 
write this Essay, I am relying on the fact that the intended readers (mostly legal academics) will know the conventional semantic meanings of most of the words and phrases that I use, as well as the conventional syntax of English. Moreover, I am counting on their knowledge of some specialized vocabulary, such as the word "originalism" and the phrase "original public meaning." At some points, I use conventional semantic meanings to build stipulated meanings, such as "interpretation" and "construction"-based on the assumption that some of the readership will be unfamiliar with the technical sense in which those words are used in contemporary legal theory. In addition, I can rely on a shared context of communication. I can assume my primary intended audience is aware of the general contours of contemporary constitutional theory, general facts about the Constitution itself, and so forth.

\section{Meaning as a fact.}

This account of communicative meaning has the consequence that the communicative content of the constitutional text is a fact. In some cases, there may be epistemic difficulties with discovering the communicative content. Whether we can fully recover the communicative meaning of a particular clause is contingent on our access to the relevant evidence. But the possibility of epistemic difficulty does not clash with the proposition that the communicative meaning is a fact in the sense in which facts are sometimes contrasted with values. ${ }^{29}$

Thus, interpretation is a factual inquiry that yields communicative content, whereas construction is a norm-guided activity that yields constitutional doctrines, decisions in constitutional cases, and constitutionally salient actions by officials. ${ }^{30}$

\section{F. The Need for Rigorous Methods}

One of the complaints about originalism is that it lacks rigorous methods and is subject to manipulation. "Originalists simply dress up their political preferences in historical clothes" is one possible articulation of the critique. This point is reinforced by the historian's lament about "law office history" and the tendency of advocates to cherry-pick the standard sources for a few quotations

\footnotetext{
29 For a discussion contrasting facts with values, see Philip S. Gorski, Beyond the Fact/Value Distinction: Ethical Naturalism and the Social Sciences, 50 Society 543, 54446 (2013).

30 For a discussion of constitutional construction, see Part IV.
} 
that support an originalist argument for their side of the case. ${ }^{31}$ These are all legitimate worries, and they suggest the need for originalists to develop a rigorous set of methods and protocols. This Essay focuses on the methods, but an equally important task is the articulation of protocols for originalist scholarship, including the principles that all of the salient evidence (for and against the author's hypothesis) should be reported and that underlying data should be made publicly available.

\section{Methods For Determining Conventional Semantic MEANING}

Originalist methodology can draw on the natural capacity of constitutional interpreters to understand English, but it must also take into account the difficulties that face any reader who attempts to discover the communicative content of an old text written for a different audience. Some of the problems are related to the recovery of the original context of constitutional communication; those problems are discussed in Part III of this Essay. This Part addresses semantics, the conventional meanings of the words and phrases that make up the constitutional text.

A. The Role of Conventional Semantic Meaning in Public Meaning Originalism

What are "conventional semantic meanings"? Naïve originalist practice sometimes treats conventional semantic meaning as if it were determined by dictionary definitions, but this view is false. Dictionaries report usage, and these reports can be accurate or inaccurate. Conventional semantic meanings are determined by patterns of usage that may change over time as a result of what is called "linguistic drift." 32 When a word or phrase is used in its conventional sense, the relevant patterns of usage are those of the linguistic community to which the author belongs at the time the text is written.

We can distinguish between ordinary meanings and technical meanings. When a word or phrase is used in an ordinary sense, the usage is that of a linguistic community: for example, speakers

31 Saul Cornell, Heller, New Originalism, and Law Office History: "Meet the New Boss, Same as the Old Boss”, 56 UCLA L Rev 1095, 1098-1102, 1110-12 (2009).

32 For an illustration of linguistic drift, see Sol Steinmetz, Semantic Antics: How and Why Words Change Meaning 49-50 (Random House 2008) (explaining the changing meaning of the word "deer" in the thirteenth century). 
of eighteenth-century American English. Some words have technical meanings, which are accessible to a linguistic subcommunity of specialists; lawyers and judges form such a community. The phrase "Letters of Marque and Reprisal" used in Article I, § 8 of the US Constitution ${ }^{33}$ has a technical meaning. ${ }^{34}$

Meanings can vary in other ways. In American English, the words "pop," "soda," and "coke" are all used as generic terms to refer to flavored carbonated beverages, but which term is favored varies regionally. Some patterns of regional variation may be so distinctive that they constitute "dialects." 35 Systematic variations also occur along other dimensions, including socioeconomic, ethnic, and religious groupings. ${ }^{36}$ Public meaning originalism makes an empirical assumption that the conventional semantic meanings employed in the constitutional text were accessible to a wide range of Americans at the time each provision was framed and ratifiedeven if many readers also communicated using a dialect. ${ }^{37}$

Syntax (or grammar) and conventions regarding punctuation also play a role in the production of meaning. A famous example of the possible effect of punctuation conventions is found in Article IV, $\S 3$, Clause 1 , for which the choice of a comma or semicolon arguably has a substantial effect on the meaning of the clause. ${ }^{38}$ Although these issues must be addressed by originalist methodology, they are bracketed here.

33 US Const Art I, § 8, cl 11.

34 See Jules Lobel, Covert War and Congressional Authority: Hidden War and Forgotten Power, 134 U Pa L Rev 1035, 1043-46 (1986).

35 See Walt Wolfram and Natalie Schilling, American English: Dialects and Variation 397 (Wiley 3d ed 2016) (defining "dialect" as "[a] variety of a language associated with a particular regional or social group”).

36 See id.

37 The assumption is that the conventional semantic meanings of the words and phrases in the Constitution might be empirically tested in various ways. For example, the methods of corpus linguistics might be employed to determine whether these words are present in sources that reflect usage by various groups. See generally James C. Phillips, Daniel M. Ortner, and Thomas R. Lee, Corpus Linguistics \& Original Public Meaning: A New Tool to Make Originalism More Empirical, 126 Yale L J F 21 (2016). Giving a full account of the empirical foundations of the public accessibility assumption is beyond the scope of this Essay.

38 See Vasan Kesavan and Michael Stokes Paulsen, Is West Virginia Unconstitutional?, 90 Cal L Rev 291, 295 (2002) (explaining how rules of grammar and punctuation suggest that West Virginia's creation did not conform to the plain meaning of the Constitution). 


\section{B. Methods for Originalist Semantics}

How can originalist methodology discover the conventional semantic meanings of the constitutional text given the problem of linguistic drift?

\section{Linguistic intuitions.}

Although some provisions of the constitutional text were drafted in 1787, the semantic content of most of these provisions is accessible to contemporary linguistic intuitions. Moreover, the text of the Constitution continues to circulate and affect linguistic practices. The original meanings of some constitutional provisions may thus be active today in the production of contemporary conventional semantic meanings. We have no problem understanding Article I, § 2's statement of the qualifications for members of the House of Representatives: "No Person shall be a Representative who shall not have attained to the Age of twenty five Years, and been seven Years a Citizen of the United States, and who shall not, when elected, be an Inhabitant of that State in which he shall be chosen." ${ }^{39}$ As competent speakers of the natural language English, we deploy our prereflective linguistic intuitions to parse this text. Because of linguistic continuity, these intuitions seem (at least on the surface) to yield the original meaning.

Even in cases of linguistic drift, linguistic intuitions plus immediate context may enable a contemporary reader to recover the original meaning. Take the well-known case of "domestic Violence" in Article IV, $\S 4.40$ The contemporary meaning of the phrase refers to violence within a family, such as spousal, child, and elder abuse, but contemporary readers are able to glean the original meaning-roughly, riots, rebellions, and insurrections within the territory of a state (as opposed to an invasion from without)-because the surrounding context makes the modern meaning highly implausible. ${ }^{41}$

But linguistic intuitions formed by immersion in modern linguistic practices can be misleading. For example, an otherwiseexcellent student note on the Seventh Amendment's "Twenty Dollars Clause" makes the mistaken assumption that the word

39 US Const Art 1, § 2, cl 2. Even this provision may contain ambiguities. See Daniel B. Rice, The Riddle of Ruth Bryan Owen, Yale J L \& Hum *9-11, 17-18 (forthcoming), archived at http://perma.cc/RE4S-PQA6 (describing the interpretive issues presented by the Qualifications Clause's seven-year provision).

40 US Const Art IV, § 4.

41 See Solum, 91 Notre Dame L Rev at 71-73 (cited in note 1). 
"dollar" refers to the contemporary Federal Reserve note, ${ }^{42}$ when in fact the word "dollar" almost certainly referred to the Spanish silver dollar weighing 416 grains and possibly other dollars with closely approximate silver content. ${ }^{43}$ The "greenback," a precursor to the modern note, was not created until much later and was the subject of much controversy, culminating in the back and forth of the Legal Tender Cases. ${ }^{44}$ Contemporary readers of the Seventh Amendment may have a strong linguistic intuition that "dollar" meant then what it means today, but that intuition is likely incorrect.

2. Dictionary definitions.

If contemporary linguistic intuitions are not a fully reliable guide to the conventional semantic meanings of the past, what about period dictionaries? At least one contemporary dictionary, the Oxford English Dictionary, is based on a comprehensive program of data collection, ${ }^{45}$ but the two dictionaries frequently used as sources for conventional semantic meanings of the constitutional provisions drafted in 1787 and the early amendments were not compiled by large teams of researchers with access to electronic databases. A Dictionary of the English Language was compiled by Samuel Johnson alone over a nine-year period and published in 1755.46 Noah Webster's 1828 An American Dictionary of the English Language borrowed from Johnson and was compiled

\footnotetext{
42 See Note, The Twenty Dollars Clause, 118 Harv L Rev 1665, 1672 \& n 43 (2005) (discussing the clause in the context of American currency, without mentioning the Spanish silver dollar).

43 In 1791, the word "dollar" likely referred to the Spanish silver dollar, as congressional acts from 1786 and 1792 indicate that the "dollar" was the Spanish silver dollar. See Act of April 2, $1792 \S 9,1$ Stat 246, 248 ("Coinage Act") (providing that dollars are "each to be of the value of a Spanish milled dollar as the same is now current"); Gold and Silver Coins, HR Rep No 23-278, 23d Cong, 1st Sess 64-65 (1834) (noting that the Articles of Confederation Congress used the Spanish silver dollar standard in 1786).

4479 US (12 Wall) 457 (1871). See also generally Juilliard $v$ Greenman, 110 US 421 (1884); Robert G. Natelson, Paper Money and the Original Understanding of the Coinage Clause, 31 Harv J L \& Pub Pol 1017 (2008) (providing an early history of money in the United States and concluding that the holdings of the Legal Tender Cases are consistent with an original understanding of the Coinage Clause).

45 See Simon Winchester, The Professor and the Madman: A Tale of Murder, Insanity, and the Making of the Oxford English Dictionary 108 (HarperCollins 1998) (recounting the "onerous" duties of volunteers collecting word lists during the creation of the Oxford English Dictionary).

46 See W. Jackson Bate, Samuel Johnson 240-60 (Harcourt Brace Jovanovich 1977).
} 
over an eighteen-year period. ${ }^{47}$ These dictionaries were magnificent achievements, but there are obvious limits on the comprehensiveness and accuracy of these attempts by single individuals to report accurately based on their intuitive knowledge and very limited sampling.

Johnson's dictionary reports English usage in Great Britain from a period that ended thirty-two years before the drafting of the US Constitution in 1787. Webster's dictionary was published thirty-eight years after the Philadelphia Convention. Neither dictionary is targeted at the most relevant data: patterns of usage in the 1780s. Nonetheless, both dictionaries provide some relevant evidence of conventional semantic meanings.

3. Corpus linguistics.

Corpus linguistics can be used to investigate semantic questions using "big data" techniques. ${ }^{48}$ In this context, "corpora" are searchable linguistic data sets. ${ }^{49}$ The application of corpus linguistic techniques to those portions of the constitutional text that were drafted from 1787 to 1803 (the original text plus the first twelve amendments) requires special effort because some of the relevant words lacked standardized spellings during this period. For example, "cruell and unusuall" was an alternative spelling of "cruel and unusual." ${ }_{50}$ Corpora relevant to interpretation of later provisions, starting with the Thirteenth Amendment (drafted in 1864), are more likely to employ standardized spellings.

Professor Randy Barnett pioneered the legal usage of corpus linguistics techniques in a 2003 article on the original meaning of the Commerce Clause; ${ }^{51}$ at that time, Barnett was unaware of the corpus linguistics literature. Recently, Justice Thomas Lee of the Utah Supreme Court has made explicit use of corpus linguistics

47 Joshua Kendall, The Forgotten Founding Father: Noah Webster's Obsession and the Creation of an American Culture 258, 303-05 (G.P. Putnam's Sons 2010).

48 See Tony McEnery and Andrew Hardie, Corpus Linguistics: Method, Theory and Practice 1-3 (Cambridge 2012); Geoffrey Sampson and Diana McCarthy, eds, Corpus Linguistics: Readings in a Widening Discipline 1-2 (Continuum 2004).

49 See McEnery and Hardie, Corpus Linguistics at 1-2 (cited in note 48).

50 See, for example, English Bill of Rights, 1 Wm \& Mary, sess 2, ch 2 (1689), in 6 Statutes of the Realm 142, 143.

51 See Randy E. Barnett, New Evidence of the Original Meaning of the Commerce Clause, 55 Ark L Rev 847, 856-65 (2003). 
as a tool in statutory interpretation. ${ }^{52}$ Stephen Mouritsen's student note is another pioneering effort. ${ }^{53}$

Corpus linguistics has several obvious advantages over linguistic intuition and dictionary definitions. The evidence provided by corpus linguistics is primary evidence of the patterns of usage themselves, whereas dictionary definitions and linguistic intuitions are secondary evidence. Corpus linguistics enables the use of quantitative methods and hence minimizes the role of subjective, qualitative judgments.

\section{Immersion.}

A fourth technique might be called "immersion." In the case of a native speaker of a natural language, immersion normally occurs very early in life and continues so long as one is a member of the linguistic community. ${ }^{54}$ Contemporary judges, lawyers, and legal scholars are not immersed in the linguistic culture of late eighteenth-century American English.

General immersion in eighteenth-century linguistic culture would be difficult. One technique would involve immersion into the written texts of the period-ideally a wide spectrum of texts, including personal diaries, fiction, newspapers, pamphlets, and written records of oral events. ${ }^{55}$ The traditional sources of information regarding framing and ratification might form part of such immersion, but acquiring linguistic competence would require exposure to a wider variety of texts. ${ }^{56}$ Whether such immersion succeeds in producing true linguistic competence is a difficult empirical question.

Partial immersion might be achieved using methods familiar from history as a discipline. This might involve consulting the usual sources and then reading relevant texts familiar to those

52 See State v Rasabout, 356 P3d 1258, 1276-77 (Utah 2015) (Lee concurring in part and concurring in the judgment). See also generally Case Note, Statutory InterpretationInterpretative Tools-Utah Supreme Court Debates Judicial Use of Corpus Linguistics.State v. Rasabout, 356 P.3d 1258 (Utah 2015)., 129 Harv L Rev 1468 (2016).

53 See generally Stephen C. Mouritsen, Note, The Dictionary Is Not a Fortress: Definitional Fallacies and a Corpus-Based Approach to Plain Meaning, 2010 BYU L Rev 1915.

54 See Ken Hale, Linguistic Aspects of Language Teaching and Learning in Immersion Contexts, in Leanne Hinton and Ken Hale, eds, The Green Book of Language Revitalization in Practice 227, 227 (Brill 2001).

55 See, for example, Daniel V. McCaffrey, Reading Latin Efficiently and the Need for Cognitive Strategies, in John Gruber-Miller, ed, When Dead Tongues Speak: Teaching Beginning Greek and Latin 113, 115-16 (Oxford 2006).

56 See Phillips, Ortner, and Lee, 126 Yale L J F at 22-23 (cited in note 37). 
sources, leading to further texts, and so forth. Partial immersion might or might not lead to full linguistic competence.

5. Application of multiple techniques.

In practice, multiple techniques can all be employed, with each acting as a kind of check on the others. Contemporary linguistic intuitions can be checked against dictionary definitions to reveal possible anomalies. Dictionary definitions can be checked against the results of corpus linguistics and those results checked against the linguistic intuitions generated by partial immersion in the relevant linguistic world via written texts. When all these techniques converge on a single hypothesis regarding the conventional semantic meaning of a word or phrase, we would have strong evidence in favor of that meaning. When the techniques do not converge, then we would look for explanations for divergence. ${ }^{57}$

\section{Semantic Meaning Is Sparse and Underdeterminative of Legal Content}

Bare semantic meanings are sparse. Lawyers are very familiar with the idea that the literal meaning of a text does not deliver the full contextual meaning. This point is related to the notion that the semantic content of a constitutional provision may underdetermine its legal effect for several reasons. First, the semantic content of many provisions may be vague or open textured; examples may include the phrase "freedom of speech" and the relationship between the phrases "legislative power," "executive power," and "judicial power." Second, the meaning of some constitutional provisions may be ambiguous. Third, it is possible that there are some constitutional gaps: issues with respect to which the structure of the Constitution implies that there must be a constitutional provision when no such provision exists. Fourth, it is theoretically possible that the Constitution contains contradictions: provisions with semantic content that impose inconsistent legal norms. Some of this underdeterminacy may be resolved by context-our next topic.

57 The question of how to address divergence is a difficult one, and a full answer is beyond the scope of this short Essay. An example of divergence between conventional semantic meaning and a contextual modulation is discussed below in connection with the Recess Appointments Clause. See text accompanying notes 77-79. 


\section{THE ROLE OF CONTEXT}

Linguistics and the philosophy of language distinguish between semantics and pragmatics. ${ }^{58}$ For the purposes of this discussion, I focus on one aspect of pragmatics, the role of context in the production of meaning. ${ }^{59}$

\section{A. Contextual Disambiguation}

Sometimes "ambiguity" and "vagueness" are used as synonyms and refer to a general lack of clarity. I reserve "ambiguity" for cases in which a word or phrase has more than one sense. "Vagueness" refers to situations in which a word or phrase has borderline cases. ${ }^{60}$

58 The word "pragmatic" is ambiguous. In contemporary legal theory, "pragmatism" refers to an antifoundationalist approach that is strongly associated with Judge Richard A. Posner. See generally Richard A. Posner, What Has Pragmatism to Offer Law?, $63 \mathrm{~S}$ Cal L Rev 1653 (1990). Legal pragmatism is related to the philosophical pragmatism that is associated with philosophers Professor John Dewey, Professor William James, and Charles Sanders Peirce. See Christopher Hookway, Pragmatism (Stanford Encyclopedia of Philosophy, Oct 7, 2013), online at http://plato.stanford.edu/archives/sum2016/entries/ pragmatism (visited Oct 23, 2016) (Perma archive unavailable). As used in the philosophy of language and theoretical linguistics, pragmatics is a technical term with a contested and evolving meaning. See Korta and Perry, Pragmatics (cited in note 11).

59 Pragmatics is sometimes defined as being concerned with the role or effects of context. See Korta and Perry, Pragmatics (cited in note 11). Another definition contrasts pragmatics, which is concerned with utterance tokens, with semantics, which is concerned with expression types. These two definitions are equivalent, because utterance tokens occur in contexts, whereas expression types are, by definition, acontextual. See id. For example, the expression type "freedom of speech" occurs in many different contexts, including the First Amendment. Semantic investigation of the expression type "freedom of speech" is therefore acontextual; it looks for the common element (conventional semantic meaning) that does not vary with particular contexts. On the other hand, the investigation of the utterance token "freedom of speech" as it occurs in the First Amendment takes the context into account. For the purposes of legal theory, "context" is a more appropriate frame: lawyers and judges are familiar with the idea that context adds to meaning but are likely to be confused by discussions of utterance tokens and expression types.

60 The standard philosophical analysis of "vagueness" (in the technical sense that is differentiated from "ambiguity") is that a term or phrase is vague if and only if it has borderline cases-that is, cases in which the term or phrase may or may not apply. See Roy Sorensen, Vagueness (Stanford Encyclopedia of Philosophy, Mar 12, 2012), online at http://plato.stanford.edu/archives/spr2016/entries/vagueness (visited Oct 23, 2016) (Perma archive unavailable). Lawyers sometimes use the words "ambiguity" and "vagueness" interchangeably to refer to a lack of clarity. In law, the idea of a vague legal norm is sometimes elicited via the contrasting notion of a "bright-line rule"-that is, a rule that does not produce borderline cases. A similar idea is expressed by Professor H.L.A. Hart's notion of "core" and "penumbra"-with the penumbra corresponding to the notion of the zone of borderline cases. See H.L.A. Hart, Positivism and the Separation of Law and Morals, 71 Harv L Rev 593, 607 (1958) ("There must be a core of settled meaning, but there will be, as well, a penumbra of debatable cases in which words are neither obviously applicable nor obviously ruled out."). 
1. Disambiguation in standard cases.

Ambiguity is pervasive in English, but in standard cases, context allows readers to disambiguate and hence to glean the intended meaning of a writing. In Article I, "Senate" might refer to the Roman Senate or an academic senate, but in context, it is clear that the US Constitution uses the word to refer to the institution that the Constitution itself created, the Senate that is part of Congress. ${ }^{61}$ To "assemble" can refer to the process of putting things together ("No assembly required."), or it can refer to a gathering of persons; in the context of the First Amendment, it is clear that the latter meaning is intended. "Arms" can refer to weapons or to parts of the human body; in the context of the Second Amendment, it is clear that the former meaning is intended.

\section{Irreducible ambiguity.}

In standard cases, context disambiguates, but there are nonstandard cases in which ambiguity is irreducible. Ambiguity can be intentional. For example, it is at least possible that the clauses in the Constitution that are now read as referring to slavery were intended to be ambiguous: "Person held to Service or Labour"62 might have been intended to be read in the South as a reference to slavery but in the North as a reference to bond servants and apprentices. ${ }^{63}$ Had the Constitution unambiguously referred to slavery, ratification in the North would have been more difficult, but unambiguous omission of slavery would have created problems in the South. ${ }^{64}$ Intentional ambiguity is not liquidated by context. ${ }^{65}$

Another possibility is unintentional ambiguity that is irreducible because patterns of usage are not sufficiently crystallized to create unequivocal meaning. Perhaps the phrase "natural born Citizen" 66 is an example of this kind of irreducible ambiguity. The Framers may have assumed that this phrase was a phrase of art

\footnotetext{
61 See US Const Art I, § 1.

62 US Const Art IV, $\S 2$, cl 3.

63 See Randy E. Barnett, Was Slavery Unconstitutional before the Thirteenth Amendment?: Lysander Spooner's Theory of Interpretation, 28 Pac L J 977, 998 (1997).

64 See Paul Finkelman, Sorting Out Prigg v. Pennsylvania, 24 Rutgers L J 605, 613 (1993).

65 Consider Federalist 37 (Madison), in The Federalist 231, 236 (Wesleyan 1961) (Jacob E. Cooke, ed) (explaining that all new laws are "more or less obscure and equivocal, until their meaning be liquidated and ascertained by a series of particular discussions and adjudications").

66 US Const Art II, § 1, cl 5.
} 
with a precise technical meaning when in fact the pattern of usage was highly inconsistent, possibly referring to persons born on American soil or to anyone whose citizenship attaches at birth or to persons designated as "natural born citizens" by Congress. ${ }^{67}$

Finally, some ambiguity may be irreducible because of epistemic problems. The liquidation of ambiguity by context assumes that sufficient information about the context is available, but in some cases, the written record may not be sufficiently rich. The Privileges or Immunities Clause of the Fourteenth Amendment might be an example of this problem. ${ }^{68}$ The record of the drafting and ratification process may not provide sufficient information to decide which of the possible meanings of this ambiguous phrase was communicated to the public.

\section{B. Four Forms of Contextual Enrichment}

The mechanisms of contextual enrichment are intuitively accessible to competent language users. Consider four common forms of contextual enrichment.

\section{Implicature.}

Implicature conveys communicative content that is different from the semantic content of an utterance or text. ${ }^{69}$ Consider the classic example of a letter of recommendation, written by a law professor, for a student applying for a prestigious judicial clerkship. The entire body of the letter reads as follows: "I recommend Ben. He was always on time to class and his attendance record was perfect." The semantic content of the letter consists of a speech act, recommendation, and two supporting statements regarding punctuality and regularity of attendance. But in the context in which the letter was written, much more than the literal meaning is communicated. If the best that can be said about Ben

\footnotetext{
67 See Christina S. Lohman, Presidential Eligibility: The Meaning of the NaturalBorn Citizen Clause, 36 Gonzaga L Rev 349, 353-54, 358-59 (2000/01) (describing various interpretations of the constitutional provision referring to natural born citizens).

68 See Michael Anthony Lawrence, Rescuing the Fourteenth Amendment Privileges or Immunities Clause: How "Attrition of Parliamentary Processes" Begat Accidental Ambiguity; How Ambiguity Begat Slaughter-House, 18 Wm \& Mary Bill Rts J 445, 461-70 (2009) (arguing that the ambiguous language of the Privileges or Immunities Clause may be the inadvertent result of a disorganized legislative process).

69 See Wayne Davis, Implicature (Stanford Encyclopedia of Philosophy, June 24, 2014), online at http://plato.stanford.edu/archives/fall2014/entries/implicature (visited Oct 23, 2016) (Perma archive unavailable).
} 
is that he was on time and did not miss class, the implicature is that Ben is not suitable for the position of judicial clerk.

\section{Impliciture.}

Impliciture involves situations in which what is said implicitly includes something else that is closely related.70 Professor Kent Bach gives the following examples, in which the impliciture (unstated) has been added in brackets:

Jack and Jill are married [to each other].

Bill insulted his boss and [as a result] got fired.

...

Nina has had enough [pasta to eat]. ${ }^{71}$

Thus, if someone says, "Jack and Jill are married," the [to each other] is unstated but implicit, and so forth for the other examples. Constitutional impliciture is common: Article I, $\S 9$ of the Constitution explicitly states, "No Bill of Attainder or ex post facto Law shall be passed,"72 with [by Congress] as an impliciture.

\section{Presupposition.}

Presupposition is communicative content provided by an unstated assumption or background belief that is conveyed by what is said. ${ }^{73}$ Again, examples are helpful:

Utterance: "Cass is no longer the head of OIRA." Presupposition: "Cass was once the head of OIRA."

Utterance: "Adrian should not eat meat." Presupposition: "Adrian does eat meat."

Utterance: "Lisa's wife is pregnant." Presupposition: "Lisa has a wife."

Philosophers of language distinguish between "conversational presuppositions" (also called "speaker presuppositions" or "pragmatic presuppositions") and "conventional presuppositions" (or

70 See Kent Bach, Conversational Impliciture, 9 Mind \& Language 124, 126 (1994).

71 Kent Bach, Impliciture vs. Explicature: What's the Difference? *1 (2006), archived at http://perma.cc/9FRR-KYLM.

72 US Const Art I, § 9, cl 3.

73 See David I. Beaver and Bart Geurts, Presupposition (Stanford Encyclopedia of Philosophy, Apr 1, 2011), online at http://plato.stanford.edu/archives/win2014/entries/ presupposition (visited Oct 23, 2016) (Perma archive unavailable); Bas C. van Fraassen, Presupposition, Implication, and Self-Reference, $65 \mathrm{~J}$ Phil 136, 137-39 (1968). See also generally Philippe Schlenker, Be Articulate: A Pragmatic Theory of Presupposition Projection, 34 Theoretical Linguistics 157 (2008). 
"semantic presuppositions"), which are triggered by particular words or phrases (for example, "no longer" in the first example above). ${ }^{74}$ For our purposes, we can put these technicalities to the side. The constitutional text may have a variety of presuppositions. Famously, the Ninth Amendment may presuppose the existence of "rights . . retained by the people," 75 even though the explicitly semantic content of the text does not state that such rights exist.

\section{Modulation.}

Finally, consider what is sometimes called modulation. The intuitive idea is that, in context, a conventional semantic meaning can be adjusted or modulated to fit the context-essentially, a new meaning is created (sometimes on the spot) so that an old word is used in a new way. As François Recanati observes:

Sense modulation is essential to speech, because we use a (more or less) fixed stock of lexemes to talk about an indefinite variety of things, situations and experiences. Through the interaction between the context-independent meanings of our words and the particulars of the situation talked about, contextualized, modulated senses emerge, appropriate to the situation at hand. ${ }^{76}$

In ordinary speech, modulations may be one-offs, used on a single occasion. But in the law, modulation can create a new technical meaning for a word that also has an ordinary sense.

The Constitution contains a variety of modulations-specialpurpose constitutional meanings that can be understood by paying attention to context. One example is (or hypothetically may be) the Recess Appointments Clause, which uses the word "Recess." 77 Read acontextually, a recess might be any break in the business of the Senate-even a lunch break. But in context, "Recess" is best read as a modulation, the meaning of which plays off

\footnotetext{
74 See Beaver and Geurts, Presupposition (cited in note 73).

75 US Const Amend IX.

76 François Recanati, Literal Meaning 131 (Cambridge 2004) (citation omitted).

77 US Const Art II, § 2, cl 3.
} 
the complementary term "Session." 78 The relevant sense of "recess" is a modulation of the conventional semantic meaning; it is limited to the break between sessions of the Senate. ${ }^{79}$

Finally, there is a residual category of "free enrichments" that do not fit into any of these categories. For present purposes, the category of free enrichments is set aside. ${ }^{80}$

\section{The Publicly Accessible Context of Constitutional Communication}

For public meaning originalism, the relevant context of constitutional communication is the publicly accessible context-that is, those features of the context of framing and ratification that were accessible to the public at the time each portion of the constitutional text was framed and ratified. ${ }^{81}$ This view of the relevant context follows from the account of the situation of constitutional communication sketched above. ${ }^{82}$

Consider the following features of the publicly accessible context:

- The publicly accessible context includes contextual features that are normally accessible to members of the public and therefore is not limited to those features actually accessed by all members of the public.

- The publicly accessible context does not include a variety of features of great interest to historians but not accessible to the public, including (in the case of the text from 1787) James Madison's notes of the Constitutional Convention, notes on the ratification debates that were not reported to the public, private diaries, and various texts read by individual Framers or ratifiers but not accessible to the public at large. Such material is not part of the public context but may provide evidence of the public context.

\footnotetext{
78 US Const Art II, § 2, cl 3.

79 See National Labor Relations Board v Noel Canning, 134 S Ct 2550, 2561 (2014) (deciding that the phrase "the recess," as it is used in the Recess Appointments Clause, includes both inter- and intrasession breaks "of substantial length").

80 For a discussion of free enrichments, see Allott, Key Terms in Pragmatics at 8081 (cited in note 26).

81 See Randy E. Barnett, An Originalism for Nonoriginalists, 45 Loyola L Rev 611, 627-28 (1999) (explaining that "[t]he public meaning of the words of the Constitution, as understood by the ratifying conventions and the general public, could be gleaned from a number of sources, including the records of the convention").

82 See Part I.D.3.
} 
- The publicly available context does include a variety of well-known background facts, such as the War of Independence, generally known problems that arose under the Articles of Confederation, the nature and existence of the states as political entities, and so forth.

- The full criteria for public accessibility need to be articulated and defended (a project unto itself), but it seems likely that these criteria will include a condition of reasonable accessibility such that contextual features that could be accessed only through substantial effort or at substantial cost should not be considered publicly accessible.

The better our understanding of the public context of constitutional communication, the more likely it is that our reconstruction of the original public meaning will be complete and accurate.

\section{Investigation of the Public Context}

How then can originalists investigate the public context of constitutional communication? We can begin to answer this question by examining the relationship of history as a discipline to originalist methodology. Constitutional historians need to know the semantic meaning of the constitutional text—otherwise, they may fail to grasp the meaning of the object of their inquiries. And some constitutional historians, especially those with legal training who work in the legal academy, may see the recovery of the communicative content of the constitutional text as one of their central tasks. But many historians have other concerns, including inquiries into the motives and purposes of constitutional actors, the construction of constitutional narratives that illuminate the causal processes that explain constitutionally salient events, and tracing the development of constitutional ideas over time. These inquiries intersect with originalist inquiry, but they are sometimes orthogonal to the central aim of originalism-the recovery of the original public meaning of the constitutional text.

Moreover, some of the tools and techniques favored by the academic culture of professional historians may actually divert attention from original meaning. The discipline of history rewards investigation of archival material that has not yet been minedsuch investigations create new historical knowledge. But if the archival material was not publicly accessible, it does not form part of the public context of constitutional communication. Such material might provide evidence of the public context, but this aspect 
of the material is unlikely to be the primary focus of historical investigation. Moreover, historians may be very interested in the purposes or motives of constitutional actors, but motives are not meanings in the relevant sense.

Despite the differences between the aims of originalism and the aims of history, the discipline of history has much to offer originalism. Historians immerse themselves in the events and ideas of particular periods, and this technique seems essential for the recovery of the public context of constitutional communication. Such immersion may be especially important when the Constitution uses highly abstract and potentially open-textured language, but not every question about constitutional meaning requires deep immersion for an answer. The so-called hardwired Constitution seems to consist mostly of provisions for which semantic content plus obvious contextual disambiguation does the work.

\section{ORIGINALISM AND CONSTITUTIONAL CONSTRUCTION}

Most of the distinctive work of originalist methodology concerns the recovery of original meaning, but originalism has a second and equally important task: guiding constitutional construction-the determination of legal effect in the form of the articulation of constitutional doctrine and the decision of constitutional cases.

\section{A. The Constraint Principle in Operation}

For original meaning to define constitutional practice, originalist methodology must formulate a precise version of the Constraint Principle. Different versions of originalism might formulate different versions of the Constraint Principle, but almost all originalists can agree on a minimalist form of constraint as consistency, which can be formulated as the conjunction of three requirements and three qualifications:

Requirement One: Constitutional doctrines and the decisions of constitutional cases must be consistent with the "translation set." The translation set consists of the set of doctrines that themselves directly translate the communicative content of the text into doctrine and the set of doctrines that are the logical implications of that set.

Requirement Two: All of the communicative content of the constitutional text and its logical implications must be reflected in the legal content of constitutional doctrine. 
Requirement Three: All of the content of constitutional doctrine must be fairly traceable to the direct translation set, with traceable content including precisifications, implementation rules, and default rules presupposed (or otherwise supported) by the text.

Qualification One: Requirements One, Two, and Three operate only to the extent that the communicative content of the constitutional text is epistemically accessible; they are not violated by departures from unknown communicative content.

Qualification Two: If Requirements One, Two, and Three are not satisfied, then constitutional practice should be brought into compliance with constraint over time, giving due regard to the effects of constitutional change on the rule of law.

Qualification Three: Requirements One, Two, and Three are defeasible in limited and extraordinary circumstances, as specified by the best theory of defeasibility.

Implementation of constraint as consistency requires that constitutional constructions be formulated such that no action forbidden by the communicative content be authorized by constitutional doctrine, that no action required by the text be forbidden by doctrine, and so forth. ${ }^{83}$

\section{B. Originalism and the Construction Zone}

Many originalists believe that the communicative content of the constitutional text underdetermines the full content of constitutional doctrines. ${ }^{84}$ Such underdeterminacy creates "construction zones," in which constitutional construction is required to fill in the content of provisions that are vague, open textured, or irreducibly ambiguous. Theorizing the construction zone is a large task, but one conclusion seems clear: an originalist approach to

83 For additional discussion of constraint in originalist methodology, see generally Solum, 91 Notre Dame L Rev 1 (cited in note 1); Solum, The Constraint Principle (cited in note 2).

84 See, for example, Jack M. Balkin, The Construction of Original Public Meaning, 31 Const Commen 71, 80 (2016); Caleb Nelson, Originalism and Interpretative Conventions, 70 U Chi L Rev 519, 543 (2003) (recognizing that the "members of the founding generation certainly expected some of the Constitution's rules to have different applications in different contexts") (emphasis omitted); Michael W. McConnell, The Importance of Humility in Judicial Review: A Comment on Ronald Dworkin's "Moral Reading" of the Constitution, 65 Fordham L Rev 1269, 1284 (1997) ("Mainstream originalists recognize that the Framers' analysis of particular applications [of their principles] could be wrong, or that circumstances could have changed and made them wrong."). 
the construction zone must be consistent with the normative justifications offered for the Constraint Principle. Such justifications often focus on democratic legitimacy and the rule of law. ${ }^{85}$

The following techniques suggest approaches that originalism might take in the construction zone:

- Precisification: Vague provisions can be precisified via rules that draw lines sorting borderline cases.

- Default rules: Open-textured provisions can be rendered determinate via general default rules, for example, a Thayerian default rule of deference to democratic institutions. ${ }^{86}$

- Precedent and historical practice: Within a construction zone, precedent and historical practice can liquidate the meaning of provisions that are irreducibly ambiguous or vague.

These techniques aim for consistency with the rule of law and democratic legitimacy in the construction zone.

\section{CONCLUSION}

Originalism is sometimes portrayed as an old theory, but that picture is misleading in many ways. Serious academic work on public meaning originalism as a rigorous theory really began only in the 1990s, and much of the most important work was done in the first decade of the new millennium. Indeed, originalist theory and practice continues to evolve at a rapid pace. But there remains a gap - the development of a rigorous account of originalist methodology. Such an account requires an interdisciplinary approach that critically evaluates and adapts techniques from linguistics and history but retains and modifies the sophisticated interpretive techniques that have been developed by lawyers. This Essay provides a prolegomenon to a fully developed originalist methodology.

\footnotetext{
85 For additional discussion of construction zones, see Solum, The Constraint Principle at *8, 117-18 (cited in note 2).

86 See generally Evan H. Caminker, Thayerian Deference to Congress and Supreme Court Supermajority Rule: Lessons from the Past, 78 Ind L J 73 (2003).
} 